\title{
Oral iron tolerance
}

\author{
A. B. S. MitChelL \\ M.B., M.R.C.P. \\ Charing Cross Hospital, London
}

\begin{abstract}
Summary
The tolerance of volunteer patients to various ferrous salt preparations, administered orally in equivalent doses of elemental iron, has been compared. The palatability of ferrous sulphate tablets, BP, given before meals was not improved by administration after meals, by sustained release formulation, or by substituting other ferrous salts. Intolerance was related to the number of tablets rather than to the dose of iron in a course. The liquid iron preparation was the least acceptable.

Ferrous sulphate tablets, BP, given before meals, approximate most closely to the hypothetical ideal iron preparation for therapeutic oral administration.
\end{abstract}

\section{Introduction}

Iron deficiency is common, and can be corrected by means of orally administered iron in most patients. The variety of oral iron preparations available suggests that there is no single ideal. This should be palatable and free of unwanted effects, cheap, well absorbed, and effective in raising the haemoglobin concentration in patients suffering from uncomplicated iron-deficiency anaemia.

Most ferrous salts are well absorbed when compared with ferric salts (Brise and Hallberg, 1962; Hallberg, 1970), and the side effects of reduced iron have been considered to be related to the dose and not to the particular salt used (Hallberg, Ryttinger and Sölvell, 1966; Sölvell, 1970). The optimum dose of oral iron for therapy is not defined. The amount absorbed continues to increase as the dose increases, while the ratio of absorbed to ingested iron falls when doses of oral iron are increased (Bothwell, Pirzio-Biroli and Finch, 1958; Smith and Pannacciulli, 1958; Beutler, Kelly and Beutler, 1962; Middleton, Nagy and Morrison, 1966). As the incidence of side effects of oral iron increases when the total daily dose is increased (Hallberg et al., 1966; Sölvell, 1970), the optimum is probably the maximum that can be ingested without producing side effects and, hence, defaulting.

Present address: Dr A. B. S. Mitchell, Consultant Physician, Prince of Wales Hospital, London N15 4AW.
Attempts have been made to reduce the incidence of side effects by means of sustained release preparations. As most iron absorption occurs in the upper small intestine, delaying the release of iron might well decrease absorption and this has been demonstrated in some studies (Bothwell et al., 1958; Crosland-Taylor, Keeling and Cromie, 1965; Middleton et al., 1966; Sölvell and Norrby, 1970) but not in all (Layrisse, 1963; McCurdy and Dern, 1968). Nevertheless, sustained release preparations have been shown to raise the haemoglobin concentration satisfactorily in some studies (Pote, 1958; Webster, 1962; Layrisse, 1963; Israels and Cook, 1965; Gomez and Gomez, 1967, 1969; Howardp 1970) but not in all (Beutler and Meerkreebs, 1966 Mitchell and Gill, 1974). Although increases in the haemoglobin concentration are the objective of treat ment, there is considerable individual variation in this response to therapy, which is a relatively insensitive index of effect (Brise and Hallberg, 1962; CroslandTaylor et al., 1965; Hallberg, 1970).

Perhaps the difference between the direct tests of absorption and the haematological response can be explained by the time of administration of the sustained release forms-fasting or unrelated to meals. Brise and Hallberg (1962) showed that iron taken with food is absorbed about half as well as that taken between meals. It has been considered impracticable to give ferrous sulphate tablets, BP, unrelated to meals, because of the anticipated side effects (Israels and Cook, 1965), but ferrous fumarate administered to fasting subjects has been shown to be as effective and with as few side effects as a sustained release form of ferrous sulphate (Callender, 1969). Ferrous fumarate is less soluble than ferrous sulphate, and has been reported to be as well (Brise and Hallberg, 1962) or less well (Callender and Warner, 1969) absorbed. An enhanced response might, therefore, be expected from ferrous sulphate administered to fasting subjects.

In this trial the acceptability of ferrous sulphate tablets, BP, given before or after meals, has been compared with sustained release preparations of this compound, with various other reduced iron salts, and with a placebo. 
Patients and methods

The patients were incapacitated by crippling rheumatoid arthritis and were being cared for in a residential hospital. Those who had experience of oral iron therapy were asked to volunteer for this study; fourteen did so, and completed the trial.

Nine preparations of iron were exhibited, each for a 6-day course. The dose of elemental iron averaged $100 \mathrm{mg}$ daily for the first 3 days, and 200 $\mathrm{mg}$ daily for the next 3 days; no therapy was offered on the seventh day. The iron preparations used were those available commercially, the dose of elemental iron being adjusted by varying the number of tablets (or capsules, or teaspoonfuls) offered (Table 1). Lactose tablets were offered for two periods, before one of which the patients were told that the tablets consisted of lactose and would indicate their ability to take tablets, and before the other they were told that an iron preparation had been made to resemble the lactose tablets (hereafter referred to as the placebo tablets). The number of lactose tablets offered was the same as the number of ferrous sulphate tablets, BP. All the sustained release preparations of ferrous sulphate, and one course of ferrous sulphate tablets, BP, were given before meals; all other preparations were given after meals. The order in which the preparations were offered during the 12 weeks of the trial was decided by reference to a table of random digits.

The patient volunteers knew that the trial was to discover which preparations were the more acceptable, and they were told that should any upset occur they could stop taking the treatment. The acceptability of the iron preparations was then calculated by assessing the proportion of iron taken relative to that offered. In the case of the lactose tablets this proportion related to tablets.
Results

\section{Patients}

As perhaps was to be expected with patients who freely volunteered for the trial, most took a high proportion of the preparations presented (expressed as percentages: range $71 \cdot 0-95.9$, mean $86.2, \pm 6 \cdot 85$ ), and only one of the fourteen took significantly less than the mean (at the $95 \%$ level of confidence).

\section{Duration}

The trial extended over 12 weeks and the proportion taken in any week remained high (expressed as percentages: range $69 \cdot 4-95 \cdot 9$, mean $86 \cdot 1$, $\pm 6 \cdot 54$ ), only the last 2 weeks differing significantly from the mean $(69.4 \%$ and $72.8 \%$ respectively). This was probably due to the patients' tiring of the trial. No preparation was given with undue frequency during this period, so the result was not biased. The proportion taken during the first week was also lower than the mean $(74.9 \%)$ but not significantly.

\section{Preparations}

The proportion of each preparation taken to that offered is shown in the bar chart (Fig. 1). The mean proportion taken of all preparations presented was $86.2 \%( \pm 6.35 \%)$, and only two preparations differed significantly from this-ferrous gluconate elixir $(61 \cdot 1 \%)$ and ferrous calcium citrate $(70 \cdot 8 \%)$.

\section{Discussion}

Any substance administered to patients may have unwanted side effects, even when that substance is pharmacologically inert (Green, 1964). The findings in this study confirm this observation, in that neither of the courses of lactose tablets was completely acceptable. The lactose and the placebo tablets were

TABLE 1. The amount of elemental iron in each tablet (capsule, teaspoonful) of the various iron salts and preparations presented, and the number given per course

\begin{tabular}{|c|c|c|}
\hline Iron preparation & $\begin{array}{c}\text { Dose of } \\
\text { elemental iron }(\mathrm{mg})- \\
\text { per tablet or capsule }\end{array}$ & $\begin{array}{c}\text { Number } \\
\text { per course- } \\
\text { tablets or capsules }\end{array}$ \\
\hline Ferrous fumarate (Fersamel) & 65 & 14 \\
\hline Ferrous sulphate tablets, BP & 60 & 15 \\
\hline Ferrous succinate (Ferromyn) & 37 & 25 \\
\hline Ferrous gluconate tablets, BP & 26 & 25 \\
\hline Ferrous calcium citrate ( Rarical) & 25 & 36 \\
\hline \multicolumn{3}{|c|}{ Sustained release preparations of ferrous sulphate: } \\
\hline Feospan & 45 & 20 \\
\hline Slow-Fe & 50 & 18 \\
\hline \multirow[t]{2}{*}{ Ferro-Gradumet } & 105 & 9 \\
\hline & per teaspoonful $(5 \mathrm{ml})$ & teaspoonfuls \\
\hline Ferrous gluconate elixir (Ferlucon) & 29 & 32 \\
\hline
\end{tabular}



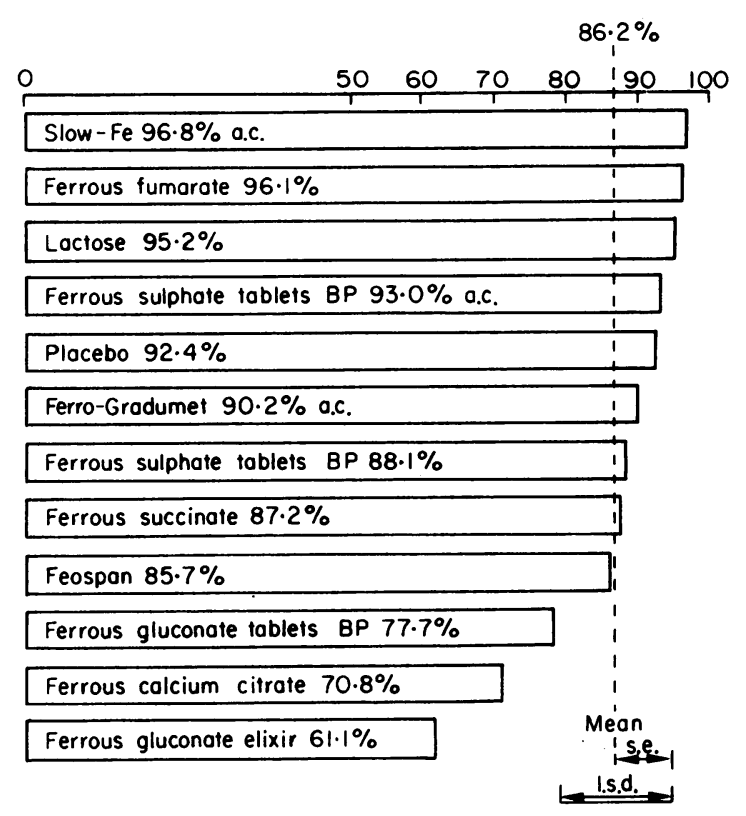

FIG. 1. Bar chart showing the proportion of each iron preparation taken during the trial period (a.c. $=$ before meals, all other preparations given with or after meals).

equally acceptable, in contradistinction to the findings of a similar study in which the lactose tablets produced virtually no side effects (Kerr and Davidson, 1958b). This can probably be attributed to the difference between the populations investigated; young, healthy nurses in the study of Kerr and Davidson (1958b) and elderly rheumatoid cripples in this study. Green (1964) found that placebos tended to increase the incidence of symptoms already present, and that these increased in frequency with age and disease.

The acceptability of the placebo tablets was also much the same as that of most iron preparations, a finding similar to that in other studies (Kerr and Davidson, 1958a, b). This could suggest that the side effects of oral iron therapy were due rather to the taking of tablets than to their content, and are psychological in origin, as has been suggested (Girdwood, 1952). However, not all studies agree with this; for example Sölvell (1970) found that oral iron therapy resulted in more side effects than did a placebo.

When the different preparations of iron in tablet form are compared, a significant inverse relationship is found between the number of tablets prescribed and those ingested (Fig. 2). This agrees with the finding that as the placebo dose increases so does the incidence of side effects (Green, 1964) and the frequency of defaulting (Maddox, 1967). Hence, those preparations containing more elemental iron per tablet have an advantage in regard to acceptability, when equivalent iron doses are administered. An apparent greater acceptability of tablets containing smaller amounts of elemental iron might be due to the smaller doses of iron taken, should a standard number of tablets be prescribed.

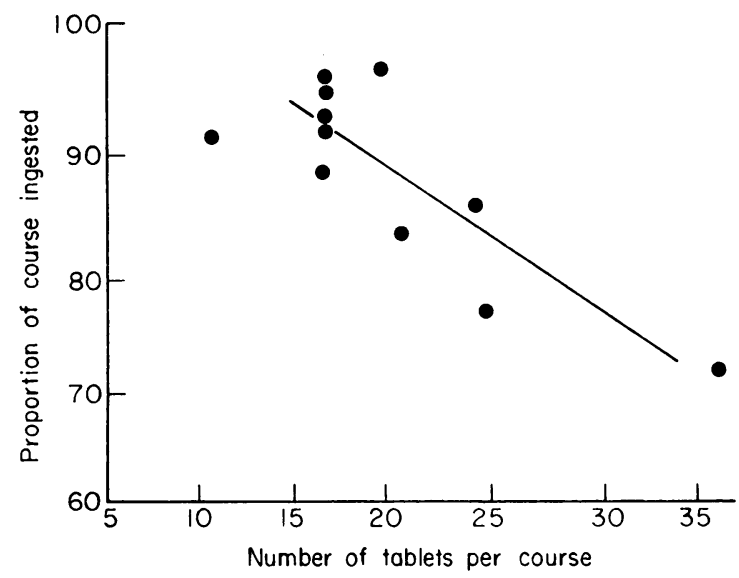

FIG. 2. Scatter diagram relating to proportion of each course to the number of tablets per course. Correlation coefficient, $0.8 ; P<0.001$.

Only the proportion of ferrous calcium citrate ingested differed significantly from the mean proport tion of all the solid preparations presented. This tablet contained the smallest amount of elemental iron per tablet and, therefore, the largest number of tablets had to be ingested. This iron salt is as well absorbed as other ferrous salts (Bothwell et al., 1958) and the preparation is formulated with tricalcium citrate as a supplement during pregnancy, and not for the treatment of iron-deficiency anaemia.

Other iron tablets in this trial were equally palatable. Notably, ferrous sulphate tablets, BP, given before meals were as acceptable as those given after meals, and as the three sustained release preparations of iron.

The only liquid preparation of iron, ferrous gluconate elixir, was significantly less acceptable than the tablets. The absorption of liquid preparations of ferrous salts is equivalent to that of plain, rapidly disintegrating tablets (Bothwell et al., 1958; Hallberg et al., 1966). As this liquid preparation is not as acceptable as tablets, it is suggested that its prescription should be reserved for patients who feel unable to take tablets, for those suffering from dysphagia and for those who, after gastric operations, require iron therapy but fail to respond to tablets of iron. Rapid gastric emptying after partial gastrectomy, and perhaps after vagotomy and drainage procedures, may reduce the absorption of iron 
tablets and yet allow a satisfactory response to iron in liquid form (Krause, 1966; Hallberg, 1970; Mitchell, 1974).

In a condition as common as iron-deficiency anaemia, the cost of therapy is significant. The therapeutic effect of oral iron therapy is related to the amount of elemental iron absorbed which is, itself, proportional to the dose of elemental iron ingested. The absorption of all the plain ferrous salts used in this investigation is equivalent, and that of sustained release preparations probably slightly less than that of the plain preparations. It is, therefore, reasonable to relate the price of each preparation to its content of elemental iron (Fig. 3). Ferrous sulphate tablets, BP, are the cheapest preparation.
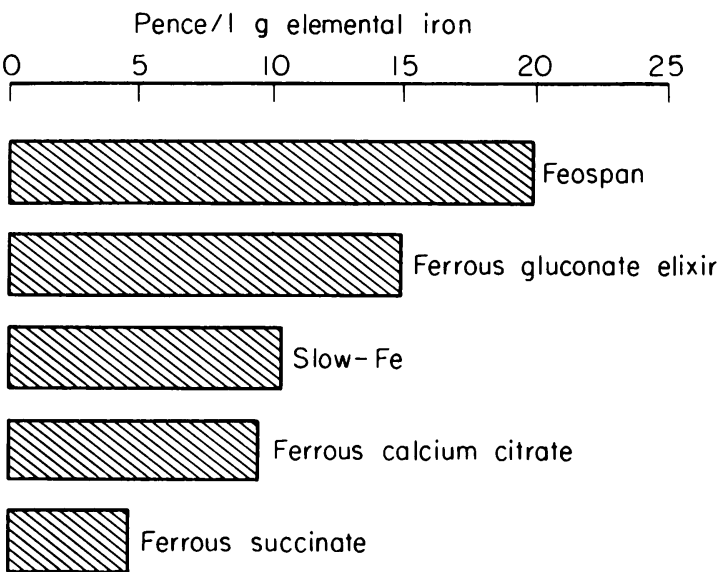

Ferro-Gradumet

Ferrous fumarate

Ferrous gluconate tablets BP

Ferrous sulphate tablets BP

FIG. 3. Cost of various iron preparations expressed as pence/g of elemental iron (January 1972).

As the side effects of oral iron are partly related to the total dose of elemental iron ingested, a method of reducing side effects while maintaining a therapeutic response, would be to stimulate absorption of the iron and hence decrease the ingestion/absorption ratio. Sorbitol and mannitol, when given in large amounts, have been shown to increase iron absorption but, unfortunately, also to increase the incidence of intolerance (Hallberg, Sölvell and Brise, 1966). Ascorbic acid has also been shown to promote iron absorption (Hallberg et al., 1966; McCurdy and
Dern, 1968), but the combination of ascorbic acid and iron appeared to result in more side effects than did iron alone (Hallberg et al., 1966). Succinic acid is the most promising promoter of iron absorption, as it appears to increase iron absorption without an increase in side effects (Brise and Hallberg, 1962; Hallberg and Sölvell, 1966; Hallberg, 1970) and its use may be considered for the small proportion of patients who find side effects of oral iron therapy troublesome.

\section{Acknowledgments}

I would like to express my appreciation to Dr V. Kendall, the nursing staff, and the patient volunteers of the Royal Home and Hospital for Incurables, Putney. I should also like to thank Miss S. B. Down for the dispensing of the iron courses and their costing, Dr A. Fenton Lewis for invaluable help with the statistical analysis, and Mr A. N. Rollason for the design and preparation of charts.

\section{References}

Beutler, E., Kelly, B.M. \& Beutler, F. (1962) Regulation of iron absorption. II. Relationship between dosage and iron absorption. American Journal of Clinical Nutrition, 11, 559.

Beutler, E. \& Meerkreebs, G. (1966) Doses and dosing. New England Journal of Medicine, 274, 1152.

Bothwell, T.H., Pirzio-Biroli, G. \& Finch, C.A. (1958) Iron absorption. 1. Factors influencing absorption. Journal of Laboratory and Clinical Medicine, 51, 24.

Brise, H. \& Hallberg, L. (1962) Absorption of different iron compounds. Acta medica scandinavica, 171, Suppl. 376, 23.

Callender, S.T. (1969) Quick and slow release iron; a double blind trial with a single daily dose regimen. British Medical Journal, 4, 531.

Callender, S.T. \& Warner, G.T. (1969) Absorption of therapeutic preparations of iron measured with a whole body counter. British Medical Journal, 4, 532.

Crosland-Taylor, P., Keeling, D.H. \& Cromie, B.W. (1965) A trial of slow-release tablets of ferrous sulphate. Current Therapeutic Research, 7, 244.

GiRdwood, R.H. (1952) Treatment of anaemia. British Medical Journal, 1, 599.

Gomez, G. \& Gomez, J. (1967) Two iron tablets compared. British Journal of Clinical Practice, 21, 31.

GoMez, G. \& Gomez, J. (1969) Anaemia in general practice: controlled-release ferrous sulphate and vitamin $C$ compared with ferrous sulphate B.P. British Journal of Clinical Practice, 23, 421.

Green, D.M. (1964) Pre-existing conditions, placebo reactions, and 'side effects'. Annals of Internal Medicine, 60, 255.

Hallberg, L., Sölvell, L. \& Brise, H. (1966) Search for substances promoting the absorption of iron. Studies on absorption and side effects. Acta medica scandinavica, 181, Suppl. 459, 11.

Hallberg, L. \& Sölvell, L. (1966) Succinic acid as absorption promoter in iron tablets. Absorption and side effect studies. Acta medica scandinavica, 181, Suppl. 459, 23.

HallberG, L. (1970) Oral iron therapy-factors affecting the absorption. In: Iron Deficiency (Ed. by L. Hallberg, H.-G. Harwerth and A. Vanotti), pp. 551-572. Academic Press: London and New York.

Hallberg, L., Ryttinger, L. \& Sölvell, L. (1966) Side effects of oral iron therapy. A double blind study of different iron compounds in tablet form. Acta medica scandinavica, 181, Suppl. 459, 3. 
Howard, H.I. (1970) A comparative trial of 'Slow Fe' and ferrous sulphate, B.P. Journal of the Royal College of General Practitioners, 20, 56.

ISRAELS, M.C.G. \& CoOK, T.A. (1965) New preparation for oral iron therapy. Lancet, ii, 654.

KERR, D.N.S. \& DAVIDSON, Sir S. (1958a) The prophylaxis of iron deficiency anaemia in pregnancy. Lancet, ii, 483.

KerR, D.N.S. \& DAVIDSON, SIR S. (1958b) Gastrointestinal intolerance to oral iron preparations. Lancet, ii, 489.

KRAUSE, U. (1966) Treatment of postgastrectomy iron deficiency anaemia with reference to the absorption of iron administered in fluid and tablet form. Acta chirurgica scandinavica, 132, 186.

LAYRISSE, M. (1963) The utilization of iron from a controlled-release dose form. Current Therapeutic Research, 5, 232.

MAdDOX, R.K. (1967) Patient cooperation in taking medicines. Journal of the American Medical Association, 199, 169.

McCurdy, P.R. \& Dern, R.J. (1968) Some therapeutic implications of ferrous sulphate-ascorbic acid mixtures. American Journal of Clinical Nutrition, 21, 284-188.

Middleton, E.J., NAGY, E. \& Morrison, A.B. (1966) Studies on the absorption of orally administered iron from sustained-release preparations. New England Journal of Medicine, 274, 136.

Mitchell, A.B.S. \& Gill, A. Morton (1974) Choice of iron therapy. The Practitioner (in press).

Pote, H.H. (1958) Sustained-release iron therapy. International Record of Medicine, 171, 87.

Smith, M.D. \& Pannacciulli, I.M. (1958) Absorption of inorganic iron from graded doses; its significance in relation to iron absorption tests and 'mucosal block' theory. British Journal of Haematology, 4, 428.

SölVELl, L. (1970) Oral iron therapy-side effects. In: Iron Deficiency (Ed. by L. Hallberg, H.-G. Harwerth and A. Vanotti), pp. 573-583. Academic Press: London and New York.

Sölvell, L. \& Norrby, B. Cited by L. Hallberg (1970) Oral iron therapy-factors affecting the absorption. In: Iron Deficiency (Ed. by L. Hallberg, H.-G. Harwerth and A. Vanotti), p. 555. Academic Press: London and New York.

WeBster, J.J. (1962) Treatment of iron deficiency anaemia in patients with iron intolerance; clinical evaluation of controlled-release form of ferrous sulphate. Current Therapeutic Research, 4, 130. 